\title{
Do Animals Have any Rights in Modern Society?
}

\author{
Siniša Franjić \\ Independent Researcher, Osijek, Slavonia, Croatia.
}

How to cite this paper: Siniša Franjić. (2022) Do Animals Have any Rights in Modern Society? Journal of Humanities, Arts and Social Science, 6(1), 67-73. DOI: 10.26855/jhass.2022.01.007

Received: December 23, 2021

Accepted: January 20, 2022

Published: February 28, 2022

*Corresponding author: Siniša Franjić, Independent Researcher, Osijek, Slavonia, Croatia.

Email: sinisa.franjic@gmail.com

\begin{abstract}
Animals have the right to be treated with respect, the right to bodily integrity and the right to freedom of movement. Violation of these rights is not morally justified regardless of the potential benefits that people consider to have. Proponents of animal rights believe that it is wrong to treat animals as consumer goods just as it is wrong to treat people the same way for the same reasons. The animal rights movement is equal to the protection of human rights. Followers of this philosophy choose not to use products derived from the use or killing of animals for food, clothing, entertainment, or scientific research. They also refuse to support or cooperate with anyone who uses or kills animals for these purposes. The struggle for animal rights is still in its beginnings. It will only succeed when people understand the true value of animals. This value does not depend solely on its usability and human perception. One should appreciate all living beings and even those who at first glance do not seem so fun, attractive or loyal. Ultimately, it all comes down to the fact that we have to face our fears, and the strongest of those fears is the course of our development after we respect the animals' rights.
\end{abstract}

Keywords

Animals, Animal Rights, Animal Protection, Animal Welfare, Law

\section{Introduction}

Throughout history humans have raised and confined animals for food, clothing and research, trained animals for entertainment, fought animals for sport, bought and sold animals for profit, and lived with animals for companionship (Schaffner, 2011). Animal law, in the broadest sense, is legal doctrine in which the legal, social or biological nature of nonhuman animals is an important factor. This area of law is quite diverse and cuts across every substantive area of the law including property, tort, contract, criminal, family, and trusts; all jurisdictional boundaries-federal, state and international; and every source of law—constitutional, statutory, regulatory and common law.

Lawyers who are interested in improving the legal status and/or treatment of animals such that their interests and inherent worth are recognized and protected directly under the law focus on a subset of animal law. The primary difference between these lawyers and other lawyers who handle cases involving animals is that the focus of these lawyers (and this text) is on the animal's own interests rather than the human owner's interests in their animal. Although this text focuses primarily on the laws of the United States, the laws of other nations, including the United Kingdom, Australasia, and the European Union, are included for comparison and contrast and to provide a somewhat global introduction to animal protection law. Rather, the goal is to survey the primary laws that protect animals, identify the themes that link them, analyze and critique them in light of their consideration and protection of animals' interests, and explore characteristics of a future legal system that would better protect animals' interests. 


\section{Characteristics}

Animals are beings that comprise a multitude of species each with very different sets of capabilities, including flight, breathing, senses of smell, sight and hearing, and means of communicating (Schaffner, 2011). Of course, humans are animals. However, when "animals" are referenced, whether it be in law or in general parlance, the reference, generally, is to every species except humans. Nevertheless, the fact that humans are animals is particularly important to an inquiry into animal law, as humans comprise a subset of the group under study. In fact, Charles Darwin, over 150 years ago, "maintained that there are no uniquely human characteristics. The difference in mind between man and the higher animals, great as it is, is certainly one of degree and not of kind." Thus, according to Darwin, the difference between human animals and nonhuman sentient animals is quantitative, differing as to the level of a given attribute, not qualitative, differing in the kind of attributes we have. Nevertheless, for purposes of this text, the term "animals" will refer to nonhuman sentient animals unless otherwise noted.

Any human who lives with an animal believes that their companion feels joy and sorrow, develops relationships, communicates, and is intuitive and smart. The divide between human and nonhuman animals is indeed much narrower than once believed. Of course, different species of animals have different levels of cognitive, emotional and moral capabilities, but what is clear is that homo sapiens are not the only species with these and other capabilities. On the other hand, nonhuman animals are quite different from human animals. They have many qualities that humans do not possess; for example, the ability to fly or to breathe under water, or heightened senses of smell, sight, and sound, and the apparent ability to predict impending disasters.

What is the relevance of these similarities and differences for purposes of moral consideration and, in turn, the law? Regardless of differences, sentient beings deserve moral consideration and at least some legal rights, whether they are human or nonhuman. Of course, our legal system is created by humans and primarily devoted to protecting human interests. Thus, as a practical and political matter when advocating for legal protections of nonhuman sentient animals, noting the human-like characteristics of animals is persuasive and helps facilitate the award of legal protections. This is because most humans agree that to the extent animals share human qualities and interests they deserve to be given equal consideration of those same interests. Doubtlessly, this argument capitalizes upon the current anthropocentric view of our society and our law. Nevertheless, until this view is altered, an advocate may use it to his or her advantage to achieve the desired goal, a law that gives equal consideration to at least those interests that nonhuman animals share with humans. However, it is important to note that to the extent sentient beings have qualities and interests different from humans they deserve proper consideration and protection of those interests as well.

\section{Animal Protection}

Legal rights can play a distinctive role in animal protection for a number of reasons (Waldau, 2011). First, legal rights are characteristically specific, because a legislature or judge in a court has had to create them. When they are created, legal rights are given some sort of definition or description so that those who must enforce them have an idea of what the lawmakers intended when creating the legal right at issue. This also means that legal rights are usually defined in a specific place that ordinary citizens can access when trying to figure out what and who existing laws protect.

Second, legal rights are usually held by someone or something. It is common to think of legal rights as held by individuals, but corporations and other collections of individuals can be the holder of legal rights.

Third, legal rights are widely believed to be the highest form of legal protection. This is not always true in actual practice for two reasons. Legal rights are not as absolute as some claim-they can be, and sometimes are, overridden by the government. (We all agree, for example, that it is acceptable to curtail the free speech rights of those tempted to yell "Fire!" in a crowded theater.) In addition, other legal protections can in some instances be even more effective than individual rights - if a society outlaws ownership of, say, chimpanzees, this legal tool can be far more effective at curtailing problems than giving a captive chimpanzee a right to be free from cruelty.

It is the psychological and political value of granting an individual "rights" that makes legal rights for animals so valuable. When a group of beings is so recognized, they have arrived in terms of not only legal protections but also political, social, and ethical protections. In this sense, legal rights are extremely important because they reinforce moral versions of animal rights. 


\section{Law}

A legal system is a complex set of principles and rules that govern human behavior (Schaffner, 2011). The law defines the rights and obligations of the government to its citizens-public law, and among citizens—private law. At the most fundamental level, human laws exist to minimize, eliminate, and at times shift the burden of harm that humans cause others. The rule of law exists as an alternative to the rule of nature based on violence and the survival of the fittest, to promote a peaceful and harm-free society.

The law derives from various sources of authority-international, constitutional, statutory, administrative, and common law-each involving the protection or regulation of different types of interests, rights, and obligations. The characteristics that distinguish the various sources of law include: (1) the drafting entity and its function-a legislature that drafts laws to govern society, a regulatory agency that enacts regulations to implement legislative prerogatives, or a judge who hears cases and decides individual disputes, (2) the scope of authority-governing a nation, a state, or individual parties, (3) the generality of the provisions-global principles as defined in constitutions or detailed specifications as found in regulations, and (4) the manner of enforcement-by a public entity or private individual. Laws governing animals are found in every legal source. The following briefly describes the attributes and purposes of each source of law in order to prepare the reader to understand, analyze, and critique the current legal landscape as it relates to and protects animals' interests. Consider which sources of law-public or private, constitutional, statutory or common law—provide the greatest opportunity for protecting animals and why. Does the current animal law regime properly capitalize on the opportunity presented by each source of law?

\section{Animal}

"Animal" is defined as: any live or dead dog, cat, monkey (nonhuman primate mammal), guinea pig, hamster, rabbit, or such other warm-blooded animal, as the Secretary may determine is being used, or is intended for use, for research, testing, experimentation, or exhibition purposes, or as a pet; but such term excludes (1) birds, rats of the genus Rattus, and mice of the genus Mus, bred for use in research, (2) horses not used for research purposes, and (3) other farm animals, such as, but not limited to livestock or poultry, used or intended for use as food or fiber, or livestock or poultry used or intended for use for improving animal nutrition, breeding, management, or production efficiency, or for improving the quality of food or fiber (Schaffner, 2011). With respect to a dog, the term means all dogs including those used for hunting, security, or breeding purposes.

Advocates of animal rights hold that the fundamental criterion for moral considerability (at least strong enough to ground rights claims) is subjecthood (Anderson, 2004). To be a subject requires not simply sentience, but the capacity to have propositional attitudes, emotions, will, and an orientation to oneself and one's future. This more stringent criterion draws the line of rights bearers at least to include the great apes, dolphins, whales, dogs, pigs, and other highly intelligent mammals, and arguably includes all mammals and birds. Subjecthood generates rights not only against the infliction of pain but to the conditions for integrity of consciousness and activity, including freedom from boredom, freedom to exercise normal capacities, freedom of movement, and the right to life. The animal rights view embodies a strong claim of equality, namely, that animals with equivalent morally relevant capacities have equal rights, regardless of species membership. In accord with deontological moral theories, these rights cannot be overridden by the aggregate interests of humans or any other beings.

Advocates of environmental ethics hold that the criterion of moral considerability is being alive, or more generally, a system of life, especially a natural one as opposed to part of the humanmade environment. Morally considerable entities generate claims to preservation and health. The environmentalist's object of concern is typically an aggregate or system: a species, an ecosystem, the biosphere. Organisms, from this perspective, are fungible, valued for their role in perpetuating the larger unit, but individually dispensable. Nonliving components of systems of living things, such as rivers and mountains, may also be valued for their role in sustaining the system, and so may be preserved at the expense of individual organisms. Sensitive to the destructive influence of human activity on natural ecosystems, environmentalists tend to focus their concern on wild animals and their habitats over domesticated animals and their habitats. They also value biodiverse and rare over degraded and common ecosystems.

\section{Animal Welfare}

Animal welfare laws regulate humans' use of animals (Schaffner, 2011). Humans use animals in a number of different ways, including for research, entertainment or exhibition, hobby, and food. Animal welfare is defined as an animal's state of well-being, or "maintenance of animals under conditions of space, environment, nutrition, and 
so forth, consistent with the physiological and social needs of the species" consistent with the Five Freedoms: freedom from (1) thirst, hunger and malnutrition, (2) discomfort, (3) pain, injury, and disease, (4) fear and distress, and (5) freedom to express normal behavior. Arguably these laws should set standards beyond the mere prohibition of cruel practices already outlawed by the anti-cruelty laws. However, this may not necessarily be the case, depending upon the requirements of the particular human use being regulated. As we noted, the anti-cruelty laws often exempt certain communities of animals, such as animals used for food or research and/or practices; for example, "accepted agricultural practices.” For these animals, the animal welfare laws provide the only legal protection available.

In the United States, the federal laws governing animal welfare are enacted by agencies, such as the United States Department of Agriculture (USDA) or the Fish and Wildlife Service (FWS), pursuant to legislative grants of power. Public enforcement is done by the same agencies with some limited opportunity for private enforcement as well. Generally, the sanction for violation of a regulation is loss of a license or permit, and/or the imposition of fines.

\section{Human Obligations}

Moral systems have evolved, in humans and other species, because cooperation and tolerance are successful strategies, especially in social species (Broom, 2016). Most people would say that we have moral obligations to humans and animals of other species. If we use a living animal in a way that gives us some benefit, we have an obligation to that animal. It is my view that human behaviour and laws should be based on the obligations of each person to act in an acceptable way towards each other person and to each animal that is used. It is better to base strategies for living on our obligations rather than to involve the concept of rights because some so-called rights can result in harm to others.

With increasing knowledge and increasing efficacy of communication there has been a change in attitudes to people with a broadening of the range of people for whom we have concerns. We also now consider that a wide range of animals deserve moral consideration. One view of animal protection occurs because the animals are considered to have some intrinsic value. For many people, certain animals are valued because of evidence for their cognitive abilities, their awareness, mental aspects of their needs and the feelings that they can have, e.g. pain, fear and pleasure. Animals vary in the extent to which they are aware of themselves and of their interactions with their environment, including their ability to experience pleasurable states such as happiness and aversive states such as pain, fear and grief. The concept of sentience affects our decisions about which animals to protect. A sentient being is one that has some ability: to evaluate the actions of others in relation to itself and third parties, to remember some of its own actions and their consequences, to assess risk, to have some feelings and to have some degree of awareness.

People are more likely to want to protect those animals that are sentient. Human opinion as to which individuals are sentient has changed over time in well-educated societies to encompass, first all humans instead of just a subset of humans, and then also: (a) certain mammals that were kept as companions, (b) animals that seemed most similar to humans e.g. monkeys, (c) the larger mammals, (d) all mammals, (e) all warm blooded animals, (f) all vertebrates and (g) some invertebrates. New knowledge about brain function and welfare has tended to show that the abilities and functioning of non- human animals are more complex than had previously been assumed so there should be some re-appraisal of which animals should be protected.

\section{Control}

Animal control laws impose requirements and restrictions on the ownership of animals (Schaffner, 2011). For example, most jurisdictions require dog owners to obtain a license for their dog, to show proof of vaccination against rabies, and to not abandon or allow their dog to run at large. Cat laws are less common, although some jurisdictions have similar laws for cats as well. Jurisdictions may also limit the number of animals a resident may own, and/or may require that the animals be sterilized to reduce the number of homeless and unwanted animals.

Enforcement of these laws can be difficult. For example, it is not uncommon for owners to fail to obtain a license for their dog and the authorities would not be aware of this unless the dog is left to run at large and seized by an officer. Since the dog is not licensed, animal control would not have a way to identify the owner. Thus, this dog is considered stray and will be held at the animal control shelter for a minimum number of days as prescribed under 
the law, generally around five days. If the owner claims the dog, animal control is then able to enforce the licensing provision and require as a condition to returning the dog that the owner obtain a license and otherwise comply with relevant laws. If the dog is not claimed by its owner, the animal becomes the property of the government and may be adopted to another owner or killed.

\section{Animal Abuse}

Confusion frequently surrounds the words 'animal abuse', because they are used to encompass a great variety of circumstances (Patronek, 2016). In addition, other terms, such as 'animal cruelty', 'maltreatment' or 'ill treatment' are also widespread.

Veterinarians are aware (sometimes uneasily) that a further complication lies in the fact that the question of whether a situation or act involving an animal is judged 'abusive' also depends on the views that human society holds on particular groups of animals. For example, attitudes on what is accepted as tolerable regarding the husbandry and slaughter of farm livestock, the trapping and poisoning of animal 'vermin', and the use of laboratory animals in scientific research are quite different from what would be regarded as acceptable in the family pets. In other words, treatment that is commonly tolerated in one group of animals might well be considered 'abusive' in another.

However, in companion animals, confusion can easily and simply be avoided by applying the tried and tested typology developed successfully by the medical profession for child abuse. It can also be used in appropriate cases in all other animal groups.

\section{Best Interest of the Animals}

Regardless of which of these practice models guides the investigation of cases, prosecution often ultimately becomes the responsibility of local law enforcement, typically under the broad oversight of a district attorney (Patronek, 2016). This can create some challenges. For example, as with police investigators, the interest, training, motivation, and expertise of prosecutors with respect to animal maltreatment varies dramatically. Some prosecutors and judges may work hand-in-hand with and/or seek input from the local non-profit that investigated the case, whereas others may nearly exclude the non-profit from substantive involvement. So in the worst possible situation, the non-profit agency may find itself responsible for bearing the cost of caring for the animals for months to years as a case winds its way through the judicial process, with little input into decisions that affect case disposition or even the welfare of the animals involved.

The problem of providing for the best interest of the animals is further compounded because animals do not have any legal status as victims of crime when maltreatment is prosecuted-technically, the crime has been committed against the state, and seized animals are legally considered as "evidence". This is also true for human crime victims, of course, but other processes have been formally established in every state to give voice to those individuals. Unlike humans who are victims of a crime, treatment and rehabilitation of seized animals may be compromised because of their evidentiary status and the misguided notion that like inanimate evidence of a crime, the "evidence" must and can be preserved. This often results in animals being confined for an extended period of time in an institutional environment where rehabilitation is difficult if not impossible while legal proceedings drag on. An inherent contradiction in this situation is that following seizure and removal from the abusive situation, the animal's condition may improve dramatically, despite the need to "preserve" evidence. This highlights the importance of careful documentation at the time of seizure.

\section{Forensics}

Forensic veterinary pathology is defined as the application of knowledge of veterinary pathology to the elucidation of evidence for the Courts (Munro, 2008). In other words, the purpose of conducting a forensic examination is: (a) to discover and record any injury, disease or abnormality, and (b) to interpret these findings in a manner that allows a Court of Law to understand the cause(s) and significance of any changes.

Forensic pathology is a highly skilled task, and veterinarians undertaking forensic post-mortem examinations must be able to demonstrate that they are competent in this field. As part of their studies at university or veterinary college, veterinary students learn the basics of post-mortem examination, but this is a meagre basis for claiming competence in a very difficult discipline. After graduation, few practising veterinarians take further qualifications in pathology. Consequently, although their clinical skills and experience develop with time, their knowledge of 
(and competence in) pathology is at best static. The end-result is that many veterinarians who undertake post-mortem examinations are at serious risk of presenting evidence that is incomplete, unconvincing or inaccurate. This is unwise in a professional sense. More importantly, the Courts may be misled.

The forensic pathologist is not required to 'prove' anything, but has the immensely responsible position of ensuring that the Court is presented with a comprehensive and as clear as possible picture of what has happened to the animal. Ideally, the forensic veterinarian should have a background in general diagnostic pathology. Without such experience of natural disease the task of guiding the Court in matters that might result in a criminal or civil conviction is made more difficult.

Guidance is provided on how to conduct a forensic examination, how to avoid some of the pitfalls, and how to assist the Courts in understanding the significance of some of the more common injuries and animal ailments.

One of the major differences between veterinary and medical forensic pathology is the sheer number of species of animals and birds that the veterinarian might be asked to examine. To be knowledgeable about all of them is an impossible expectation. However, establishing contacts with specialists, who can provide advice on species identification, feeding habits, anatomy, diseases, etc., can partially redress this difficulty. Unfortunately, there are also many gaps in the current knowledge on forensic veterinary pathology. As the interest in forensic matters continues to build, these gaps will decrease but, in the meantime, the absence of detailed accounts of tissue reactions or lesions found in specific circumstances may be perplexing. The pathologist must, therefore, be constantly aware of the limitations and be prepared to advise that findings are inconclusive or are open to alternative interpretation. This can be disconcerting for the legal profession, which relies on veterinary guidance — but that is a legal problem not a veterinary one.

In the context of forensic investigation, the 'locus' is the term used to describe the site or scene where the event occurred. Examination of the locus can help to place the incident in perspective and adds to interpretation of the post-mortem findings. However, unlike medical forensic pathologists, the veterinary pathologist is rarely invited to attend at the locus. More usually, the police or other investigators remove the cadaver from the crime scene and submit it for examination some time later. There may be little alternative in cases of wildlife crime where the incidents often occur in remote areas.

Nevertheless, it is advantageous if the veterinarian has the opportunity to examine the scene and gain at first hand an insight to the location and to the position in which the animal was discovered. Important issues, such as evidence of struggling, attempted escape or restraint, can be assessed at this time. When more than one animal has died or been killed, a site visit can be helpful in determining whether the deaths occurred at the same time or sequentially. Examination of the locus may also assist in placing the incident in a particular timeframe by observation of environmental clues associated with the body. The last two points are of relevance in, for example, investigations of suspected neglect of farm animals where cadavers are present in different pens or fields.

\section{Conclusion}

Animal rights mean that animals, like humans, have rights that cannot be sacrificed or denied, just because it could benefit others. However, the status of rights alone does not mean that these rights are absolute; animal rights, just like human rights, must sometimes be limited, and different rights can certainly come into conflict. Animal rights mean that they are not our property that we can use for food, clothing, entertainment, or for experimentation. Animal welfare allows for all of this, as long as it is done in a 'humane' way. Animals have the right to equal consideration of their interests. For example, a dog certainly has the right not to be unnecessarily hurt. It is our duty to consider and respect that right of the dog. However, animals do not always have the same rights as humans, because animal interests are not always the same as human ones, and some rights would be inapplicable to animal lives. For example, a dog has no interest in voting and therefore has no right to vote, because that would be as pointless as giving that right to children.

\section{References}

Anderson, E. (2004). “Animal Rights and the Values of Nonhuman Life” in Sustein, C. R.; Nussbaum, M. C. (eds): “Animal Rights—Current Debate and New Direction”, Oxford University Press, Inc., New York, USA, p. 278.

Broom, D. M. (2016). "International Animal Welfare Perspectives, Including Whaling and Inhumane Seal Killing as a W.T.O. Public Morality Issue” in Cao, D.; White, S. (eds.): “Animal Law and Welfare-International Perspectives”, 
Springer International Publishing AG, Cham, Switzerland, p. 46.

Munro, R., Munro, H. M. C. (2008). “Animal Abuse and Unlawful Killing-Forensic Veterinary Pathology”, Saunders, Elsevier, London, UK, pp. 1-11.

Patronek, G. (2016). “Animal Maltreatment as a Social Problem” in Levitt, L.; Patronek, G.; Grisso, T. (eds.): “Animal Maltreatment-Forensic Mental Health Issues and Evaluations”, Oxford University Press, New York, USA, pp. 11-12.

Schaffner, J. E. (2011). “An Introduction to Animals and the Law”, Palgrave Macmillan, Basingstoke, UK, pp. 5-12, 71-73, 118-119.

Waldau, P. (2011). “Animal Rights—What Everyone Needs to Know”, Oxford University Press, Inc., New York, USA, pp. 93-94. 